\title{
Two-Dimensional Iron Tungstate: A Ternary Oxide Layer With Honeycomb Geometry
}

S. Pomp ${ }^{1}$, D. Kuhness ${ }^{1}$, G. Barcaro ${ }^{2}$, L. Sementa ${ }^{2}$, V. Mankad ${ }^{1,2}$, A. Fortunelli ${ }^{2}$, M. Sterrer ${ }^{1}$, F.P. Netzer ${ }^{1}$, and S. Surnev ${ }^{1 *}$

${ }^{1}$ Surface and Interface Physics, Institute of Physics, Karl-Franzens University Graz A-8010 Graz, Austria

${ }^{2}$ CNR-ICCOM \& IPCF, Consiglio Nazionale delle Ricerche, I-56124 Pisa, Italy

\section{SUPPORTING INFORMATION}

$\underline{\text { Schematic description of the various models used in the GO approach }}$

(a)

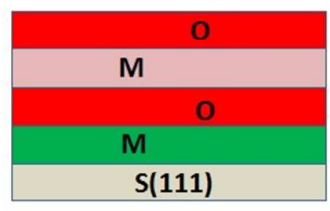

(b)

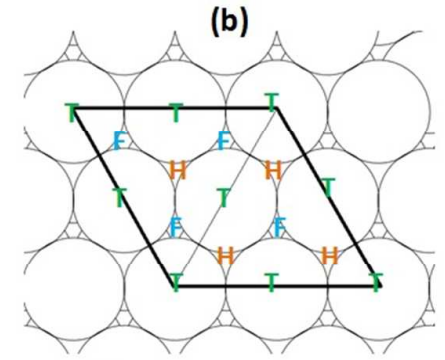

(c)

(d)

(e)

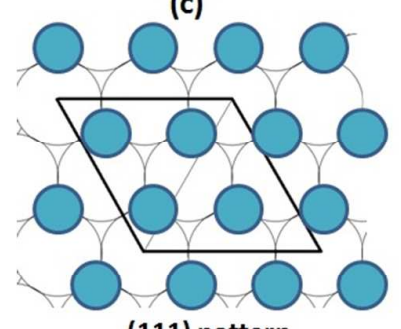

(111) pattern

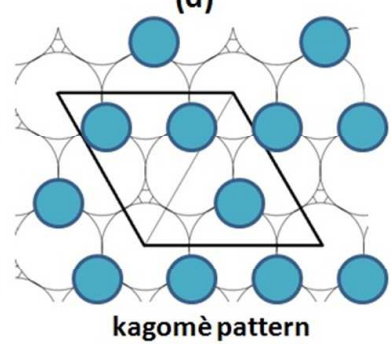

kagomè pattern

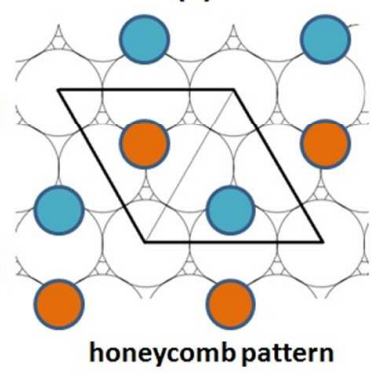

Figure S1. Schematic depiction of : (a) the multi-layer arrangement; (b) the lattice sites; (c) the (111) pattern; (d) the kagomé pattern; (e) the honeycomb pattern, assumed in our GO search for the (2x2)FeWOx phase.

\footnotetext{
${ }^{*}$ Address correspondence to svetlozar.surnev@uni-graz.at
} 


\section{$\underline{\mathrm{STM} \text { of } \mathrm{FeO} \text { on } \mathrm{Pt}(111)}$}

Figure S2 shows STM images of the FeO monolayer on $\mathrm{Pt}(111)$. The large-scale image (a) displays extended $\mathrm{Pt}(111)$ terraces, completely covered by the FeO layer, thus demonstrating its good structural quality. The high-resolution image (b) reveals a hexagonal moiré pattern with a periodicity of $25.5 \AA$ (unit cell indicated), which is due to the lattice mismatch between the $\mathrm{FeO}(111)$ layer and the Pt substrate. The bright maxima in the image (b) correspond to areas, where the Fe atoms in the film are sitting in on-top Pt positions.
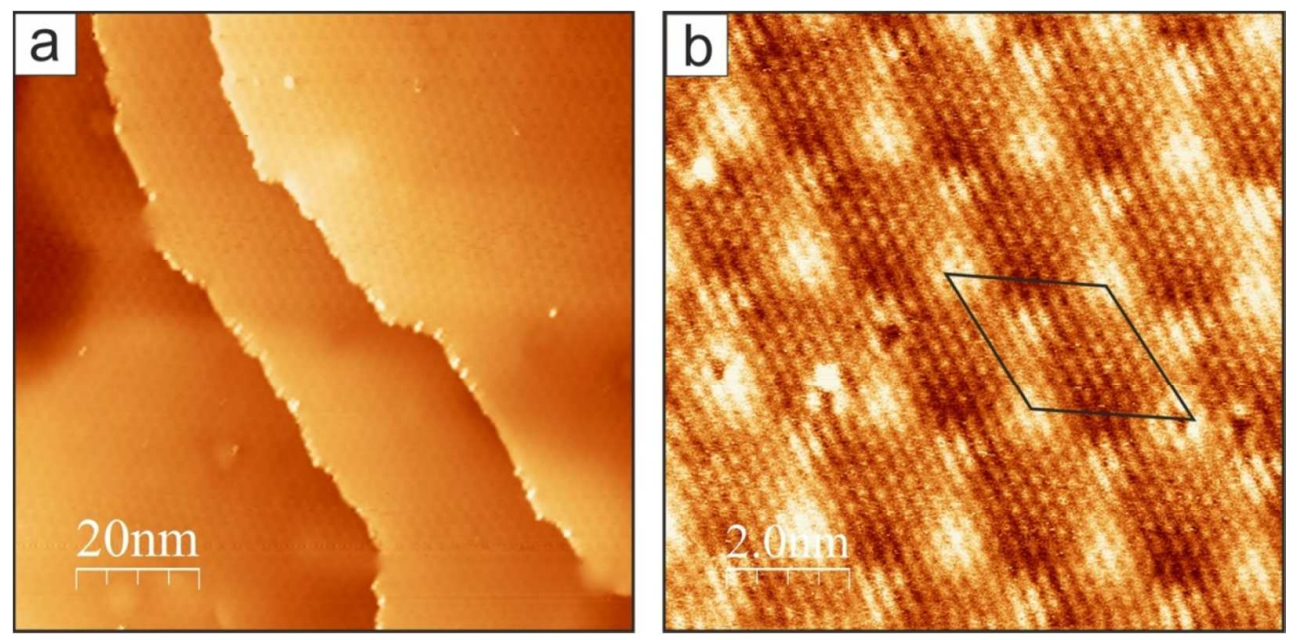

Figure S2. STM images of 1.0 ML FeO film on Pt(111): (a) $100 \times 100 \mathrm{~nm}^{2}, \mathrm{U}=2.0 \mathrm{~V}, \mathrm{I}=0.1 \mathrm{nA}$; (b) $5 \times 5 \mathrm{~nm}^{2}, \mathrm{U}=0.1 \mathrm{~V}, \mathrm{I}=1.0 \mathrm{nA}$. The moiré unit cell is indicated.

\section{$\underline{\text { XPS of FeO and FeWOx on } \mathrm{Pt}(111)}$}

Figure S3 shows a sequence of Fe $2 p_{3 / 2}$ (a) and O 1s (b) XPS spectra taken during the annealing of the $\mathrm{FeO}$ monolayer at the indicated temperatures. Prior the annealing the $\mathrm{Fe} 2 \mathrm{p}_{3 / 2}$ and $\mathrm{O} 1 \mathrm{~s}$ spectra display peak maxima at binding energies of $709.8 \mathrm{eV}$ and $529.7 \mathrm{eV}$, respectively. No changes are observed in the spectra upon annealing to $1023 \mathrm{~K}$, but above this temperature both the $\mathrm{Fe} 2 \mathrm{p}_{3 / 2}$ and $\mathrm{O} 1 \mathrm{~s}$ intensities drop abruptly to zero, due to the $\mathrm{FeO}$ film decomposition. Selected spectra from Fig. 2c (top panel) are displayed in Fig. S3(c) to allow better visibility of the corresponding fits. 

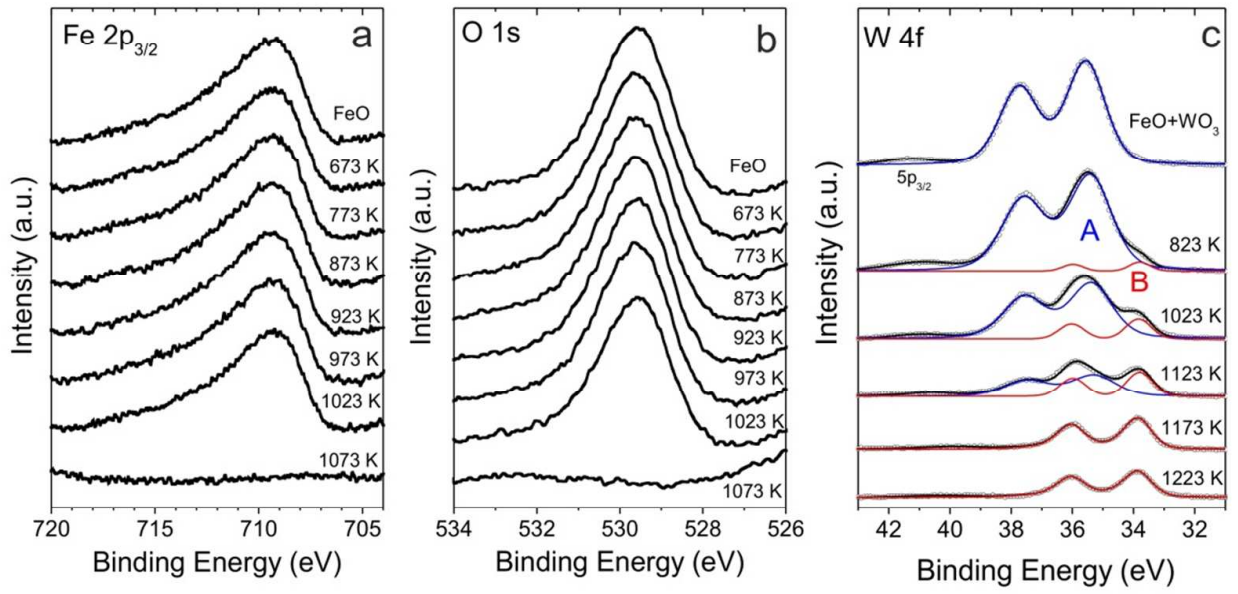

Figure S3. Sequence of $\mathrm{Fe} 2 \mathrm{p}_{3 / 2}$ (a) and $\mathrm{O}$ 1s (b) XPS spectra taken during annealing of the $\mathrm{FeO}$ monolayer at the indicated temperatures in UHV. Fig. S3(c) shows selected W $4 \mathrm{f}$ spectra taken from Fig. 2(c) for better visibility of the corresponding fits.

\section{$\underline{\text { TPD spectra }}$}

Figure S4 shows oxygen thermal desorption spectra from the isotopically labelled $\mathrm{Fe}^{18} \mathrm{O}$ monolayer for different $\left(\mathrm{W}^{16} \mathrm{O}_{3}\right)_{3}$ coverages deposited at $300 \mathrm{~K}$. Three different QMS signals with $\mathrm{m} / \mathrm{e}=32$ (Fig. S4a), $\mathrm{m} / \mathrm{e}=34$ (Fig. S4b), and $\mathrm{m} / \mathrm{e}=36$ (Fig. S4c) have been simultaneously recorded during the TPD runs. The integrated area under the different TPD traces is plotted as a function of the $\left(\mathrm{WO}_{3}\right)_{3}$ coverage in Fig. S4d. The oxygen desorption spectrum with $\mathrm{m} / \mathrm{e}=36$ from the pristine $\mathrm{FeO}$ layer (Fig. S4c) displays a narrow peak at 1170 $\mathrm{K}$ (the presence of TPD traces in the $\mathrm{FeO}$ desorption spectra with $\mathrm{m} / \mathrm{e}=32$ (Fig. S4a) and $\mathrm{m} / \mathrm{e}$ $=34$ (Fig. S4b) is due to the limited purity of the ${ }^{18} \mathrm{O}_{2}$ gas). Note that this desorption maximum is not in conflict with the XPS results of Fig. S2(a,b), due to the different desorption kinetics employed in the XPS (long annealing) and TPD (fast heating rate) experiments. The oxygen desorption maximum of the $0.5 \mathrm{ML}\left(\mathrm{WO}_{3}\right)_{3}$ covered $\mathrm{FeO}$ layers occurs at $\sim 1200 \mathrm{~K}$ and shifts to lower temperatures for higher $\mathrm{WO}_{3}$ coverages. In particular, the $\mathrm{m} / \mathrm{e}=32$ spectra exhibit a significant broadening towards lower temperatures with increasing $\left(\mathrm{WO}_{3}\right)_{3}$ coverage, which we attribute to oxygen desorption due to the partial thermal decomposition of thicker $\left(\mathrm{WO}_{3}\right)_{3}$ films. The larger part of $\left(\mathrm{WO}_{3}\right)_{3}(\mathrm{~m} / \mathrm{e}=232)$ sublimes above $900 \mathrm{~K}$, but could not be detected here, since our QMS is limited to mass 200 . The presence of significant $\mathrm{m} / \mathrm{e}=34$ signals (particularly at low $\left(\mathrm{WO}_{3}\right)_{3}$ coverages) is a clear signature of oxygen scrambling from the $\mathrm{Fe}^{18} \mathrm{O}$ layer and $\left(\mathrm{W}^{16} \mathrm{O}_{3}\right)_{3}$ clusters. 

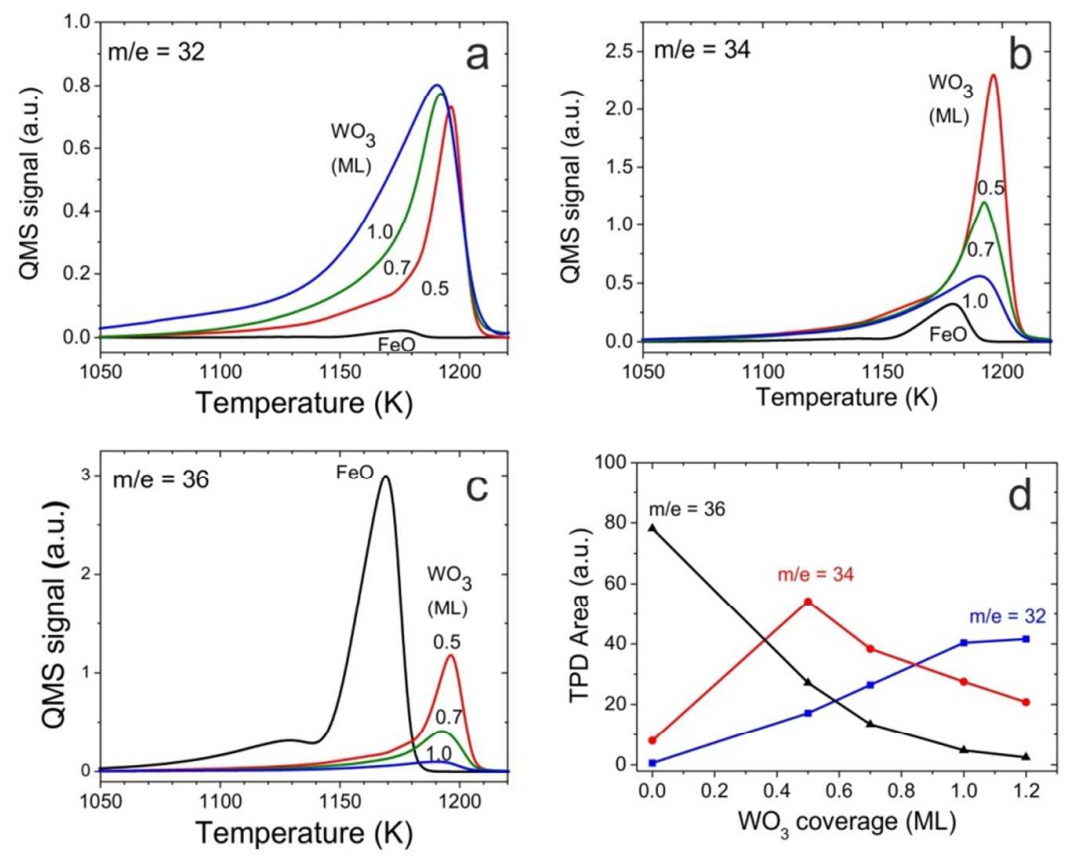

Figure S4. Oxygen thermal desorption spectra (heating rate $\beta=3 \mathrm{~K} / \mathrm{s}$ ) from isotopically labelled $\mathrm{Fe}^{18} \mathrm{O}$ monolayer for different $\left(\mathrm{W}^{16} \mathrm{O}_{3}\right)_{3}$ coverages: (a) $\mathrm{m} / \mathrm{e}=32 \mathrm{amu}$; (b) $\mathrm{m} / \mathrm{e}=34 \mathrm{amu}$ and (c) $36 \mathrm{amu}$; (d) Area under the TPD traces plotted versus the $\left(\mathrm{WO}_{3}\right)_{3}$ coverage.

\section{$\underline{\text { Self-limited growth of } \mathrm{FeWO}_{3}}$}

Figure S5 provides the spectroscopic evidence for the self-limited growth of the $(2 \times 2)-\mathrm{FeWO}_{3}$ phase with respect to the $\left(\mathrm{WO}_{3}\right)_{3}$ coverage. Here, Fe $2 \mathrm{p}_{3 / 2}$ (a), O 1s (b), and $\mathrm{W} 4 \mathrm{f}$ (c) XPS spectra of FeO layers, covered with $0.6 \mathrm{ML}$ and $1.0 \mathrm{ML}\left(\mathrm{WO}_{3}\right)_{3}$ and annealed to $1173 \mathrm{~K}$ to form the $(2 \times 2)$ structure, are presented. Obviously, the spectra corresponding to these two coverages are virtually identical.
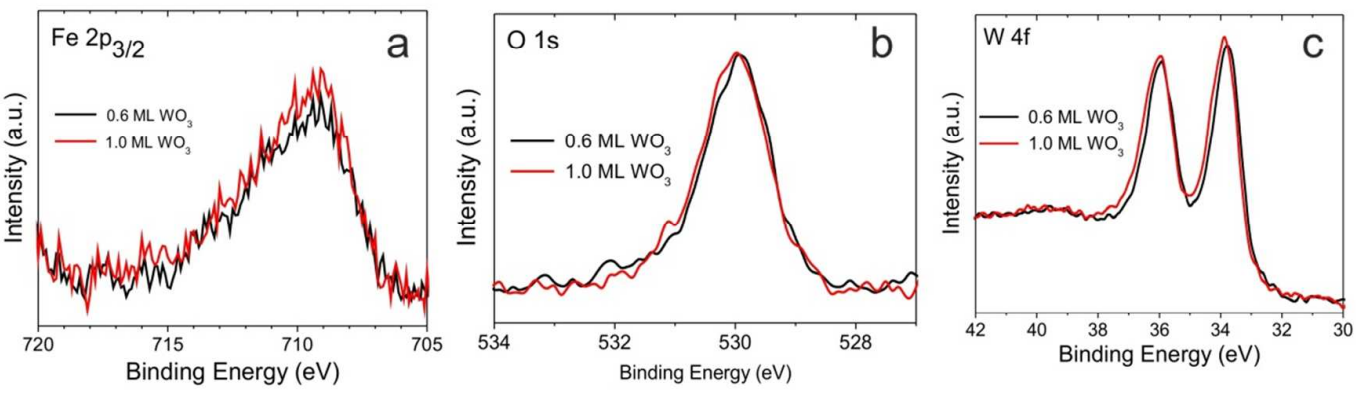

Figure S5. $\mathrm{Fe} 2 \mathrm{p}_{3 / 2}$ (a), O 1s (b) and W $4 \mathrm{f}(\mathrm{c})$ XPS spectra of (2x2)-FeWOx layers, obtained at two different $\left(\mathrm{WO}_{3}\right)_{3}$ coverages. 


\section{Discussion of STM contrast in the (6x6) phase}

The experimental STM images (Fig. 6) present an overall 3-fold symmetry with hexagonal dark holes alternating with smaller hexagons filled by bright triangular features pointing alternatively in opposite directions, and the filled hexagons are separated by linear bright features. The simulated STM image (Fig. 8) using the proposed model reproduce all these details: the bright triangular features inside the small hexagons are given by the merging of the spot produced by a central $\mathrm{W}$ atoms (in an on-top position with respect to the substrate) with three $\mathrm{O}$ atoms exactly in the same way as in the $(2 \times 2)$ phase, whereas the linear bright features that separate the hexagons are given by $2 \mathrm{~W}$ atoms (in bridge positions) together with a central bridge $\mathrm{O}$ atom. The $\mathrm{W}$ atoms give a strong contribution to the STM image as they occupy bridge or top positions with respect to the underlying metal surface; on the contrary, the Fe atoms occupy only hollow positions and basically do not contribute to the STM pattern due to their lower height. 